\title{
OPEN Social vulnerability in persons with chronic hepatitis $C$ virus infection is associated with a higher risk of prescription opioid use
}

\author{
Adeel A. Butt ${ }^{1,2,3,4 \bowtie, \text { Peng Yan }^{1} \text {, Shashi Kapadia }}{ }^{2}$, Abdul-Badi Abou-Samra ${ }^{4}$, \\ Naveed Z. Janjua ${ }^{5,6}$ \& Said Ibrahim ${ }^{2}$
}

Prescription opioid use (POU) is often a precursor to opioid use disorder (OUD) and subsequent consequences. Persons with chronic hepatitis $\mathrm{C}$ virus infection ( $\mathrm{CHC}$ ) may be at a higher risk of POU due to a higher comorbidity burden and social vulnerability factors. We sought to determine the burden of POU and associated risk factors among persons with $\mathrm{CHC}$ in the context of social vulnerability. We identified $\mathrm{CHC}$ persons and propensity-score matched $\mathrm{HCV}$ - controls in the electronically retrieved Cohort of HCV-Infected Veterans and determined the frequency of acute, episodic long-term and chronic long-term POU and the prevalence of social vulnerability factors among persons with POU. We used logistic regression analysis to determine factors associated with POU. Among $160,856 \mathrm{CHC}$ and 160,856 propensity-score matched $\mathrm{HCV}$-controls, acute POU was recorded in $38.4 \%$ and $38.0 \%(P=0.01)$ respectively. Episodic long-term $P O U$ was recorded in $3.9 \%$ in each group $(P=0.5)$, while chronic long-term $P O U$ was recorded in $28.4 \%$ and $19.2 \%(P<0.0001)$. $\mathrm{CHC}$ was associated with a higher risk of chronic long-term POU (OR 1.66, 95\% $\mathrm{Cl} 1.63,1.69)$, but not with acute or episodic long-term POU. Black race, female sex and homelessness were associated with a higher risk of chronic long-term POU. Presence of $\geq 1$ factor was associated with a higher risk of all POU patterns. Persons with $\mathrm{CHC}$ have more social vulnerability factors and a higher risk of chronic long-term POU. Presence of $\geq 1$ social vulnerability factor is associated with a higher risk of POU. Downstream consequences of POU need further study.

Opioid use disorder (OUD) has emerged as a major health threat in the United States ${ }^{1-6}$. Nearly $1 \%$ of the population ( $>2.5$ million persons) suffer from OUD with over 67,367 opioid related deaths reported in $2018^{7-9}$. Prescription opioid use (POU) has increased in the US in recent years with devastating individual and societal consequences and precedes OUD in a substantial proportion of persons $s^{1,2,10,11}$. There is evidence that the growing OUD epidemic is strongly associated with an increase in the incidence of chronic hepatitis $\mathrm{C}$ virus (CHC) infection ${ }^{12-14}$. In the US, annual incidence of HCV infection increased from 0.3 to 0.7 cases per 100,000 persons between 2004 and 2014, concurrent with a nearly fourfold increase in treatment admissions for prescription opioid injection use ${ }^{14}$.

Persons with CHC are more likely to have a diagnosis of major psychiatric illness, hazardous alcohol use and drug abuse or dependence ${ }^{15,16}$. The confluence of $\mathrm{CHC}$ infection, POU and psychiatric illness poses a unique and specific challenge, exacerbated by the social vulnerability of the persons who are affected by these conditions singly or in any combination thereof. Socially vulnerable populations are groups and communities at a higher risk for poor health, or consequences of illness, as a result of social, cultural, economic, political and environmental disparities. Socially vulnerable populations have been shown to suffer significant disparities in linkage to treatment and clinical outcomes for various conditions ${ }^{17-23}$. Since POU frequently precedes OUD and the consequences associated with OUD, it is important to understand the magnitude and risk factors associated with POU. The temporal association between HCV and POU is complicated and bidirectional, with each being a risk factor for the other. The aim of our current study to determine the burden of POU and associated risk

${ }^{1}$ VA Pittsburgh Healthcare System, Building 30, Mailstop 151, University Drive C, Pittsburgh, PA 15240, USA. ${ }^{2}$ Weill Cornell Medical College, New York, NY, USA. ${ }^{3}$ Weill Cornell Medical College, Doha, Qatar. ${ }^{4} \mathrm{Hamad}$ Medical Corporation, Doha, Qatar. ${ }^{5}$ University of British Columbia, Vancouver, BC, Canada. ${ }^{6}$ British Columbia Centre for Disease Control, Vancouver, BC, Canada. ${ }^{\circledR}$ email: aab2005@qatar-med.cornell.edu 
factors among Veterans with CHC infection and matched controls. We did not study the temporal associations of the risk variables in the current study.

\section{Methods}

Data sources and cohort construction. We used the Electronically Retrieved Cohort of HCV Infected Veterans (ERCHIVES) as the data source for this analysis. ERCHIVES is well defined in numerous previous publications ${ }^{24-29}$. Briefly, all persons with HCV infection in the Department of Veterans Affairs healthcare system (VA) diagnosed after October 1, 2001 are identified based on a positive HCV antibody test. Age (5-year blocks), sex and race matched persons with a negative HCV antibody test in the same year are identified as controls. Demographic, clinical, laboratory, pharmacy, anthropometric, vital signs and survival date are retrieved from the Corporate Data Warehouse (CDW) using well established algorithms and definitions. The cohort is updated annually to identify newly diagnosed cases with HCV infection and corresponding controls.

For the current study, we included all persons in ERCHIVES identified between 2001 and 2019. For persons with $\mathrm{HCV}$, we retained those with at least one detectable HCV RNA, thus fulfilling the criteria for CHC infection. For both groups (those with and without $\mathrm{CHC}$ ), we excluded those with human immunodeficiency virus coinfection and those with missing data to calculate FIB-4 score within 12 months prior to cohort entry date. A propensity score was calculated for each study participant using a logistic regression model including age, race, sex, body mass index, FIB-4, diabetes, hypertension, coronary artery disease, smoking status and alcohol use disorder. Using the propensity score, we conducted propensity score matching to create 1:1 matched sets of persons with $\mathrm{CHC}$ and uninfected controls using a propensity score distance. The tails of the propensity scores were not trimmed. We used the greedy matching ( $\mathrm{CHC}$ selected at random first, then $\mathrm{HCV}-$ whose propensity score is closest to the randomly selected CHC is chosen for matching), matching without replacement (once an $\mathrm{HCV}$ - has been selected to be matched, that HCV - is no longer available for selecting), and without restriction for the maximum difference between the propensity scores of matched $\mathrm{CHC}$ and HCV-.

Primary outcome measures. Our primary outcome measures were acute and long-term prescription opioid use (POU). All opioids approved by the US Food and Drug Administration were included when determining POU (list available as Appendix 1 in accompanying supplementary materials). Acute POU was defined as an episode whereby an opioid was prescribed with less than 90 days of drug supply. Long-term POU was defined as at least one episode with $\geq 90$ days of drug supply including refills. Long-term POU was further subdivided into episodic and chronic use. Episodic long-term use included the subset of persons receiving $\geq 90$ days of POU supply with $<50 \%$ episode intensity, where episode intensity was calculated as percentage of episode days covered by the prescription. Chronic long-term use included the subset of persons receiving $\geq 90$ days of POU supply with $>50 \%$ episode intensity.

Clinical covariates. Diabetes was defined using a combination of blood glucose measurements, prescription of insulin or oral hypoglycemic and ICD-9/10 $\operatorname{codes}^{27,30}$. We used FIB-4 to estimate the severity of liver disease and presence of cirrhosis. FIB-4 score was calculated based on clinical and an average of two lab values recorded within 12 months preceding entry into the cohort ${ }^{31}$. Psychiatric illness (major depression, schizophrenia, bipolar disorder, post-traumatic stress disorder), alcohol use disorder, hypertension, cancer diagnosis and cardiovascular disease were defined by presence of at least one inpatient or two outpatient International Classification of Diseases, 9th edition, Clinical Modification (ICD-9CM, prior to October 1, 2015) or ICD-10 (from October 1, 2015 onwards) codes ${ }^{32}$. Smoking history was retrieved from the Health Factors Dataset and classified as never, former and current smokers ${ }^{33}$. Since opioid analgesics are often prescribed for short term pain relief after dental procedures and fractures, we identified persons who underwent removal or restoration of teeth and those who sustained major joint dislocation or bone fracture using ICD-9CM and ICD-10 codes.

Social vulnerability factors. For our current study, we identified the following factors to denote social vulnerability: (1) non-White race; (2) female sex; (3) homelessness; (4) poverty, defined as annual income less than $\$ 45,200$ thus placing them in the low income or below Federal poverty level; (5) rural or highly rural residence; (6) alcohol use disorder; and (7) diagnosis of psychiatric illness. These variables were retrieved from the CDW datasets where they are recorded based on VA's established algorithms. These factors were chosen to represent persons with social vulnerability since persons with these characteristics have been shown to suffer significant disparities in linkage to treatment and clinical outcomes for various conditions ${ }^{17-23}$.

Statistical analyses. Baseline characteristics of persons with $\mathrm{CHC}$ and uninfected controls, and persons with and without POU were compared using chi-squared test for dichotomous variables and $t$-test for continuous variables. We determined the proportion of persons with acute, episodic long-term and chronic long-term POU by number of social vulnerability factors. We also determined the number of social vulnerability factors present among those with $\mathrm{CHC}$ only, $\mathrm{CHC}$ with $\mathrm{POU}$ and $\mathrm{POU}$ without $\mathrm{CHC}$. We used logistic regression to generate odds ratios and 95\% confidence intervals for factors associated with acute or long-term POU. Covariates of interest were demographic and clinical characteristics at baseline. All statistical analyses were completed using SAS Version 9.4 (SAS Institute Inc., Cary NC).

Missing data. There were 1707 (0.5\%) participants with missing income data and $446(0.1 \%)$ with missing data on their residence. These persons were not excluded form the main analysis since they comprised a very small proportion of the study population. We compared the baseline characteristics of persons with and without 


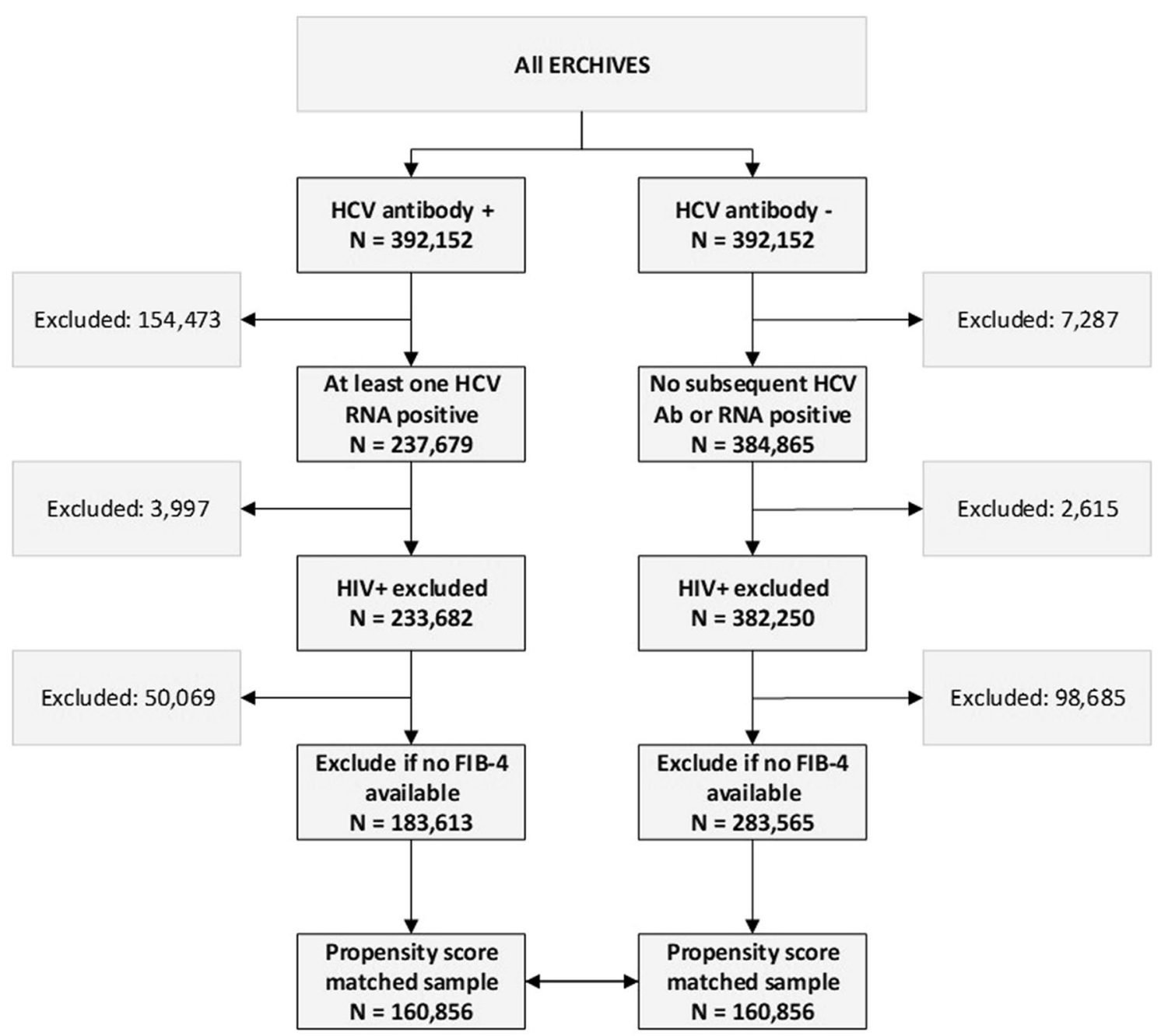

Figure 1. Cohort construction.

$\mathrm{CHC}$, and with and without POU to ensure that the overall characteristics were not different in the analysis cohort.

Ethical approval. The study was approved by the Institutional Review Board at VA Pittsburgh Healthcare System and all methods were carried out in accordance with relevant guidelines and regulations. A waiver of informed consent requirement was granted to studies related to ERCHIVES by the same Board.

\section{Results}

Baseline characteristics: CHC vs HCV-. Our final dataset included 160,856 persons with CHC and 160,856 propensity score matched controls without CHC infection (Fig. 1). Baseline characteristics of persons with CHC and uninfected controls are shown in Table 1 . Median age was 54 (IQR 49, 59) years for those with $\mathrm{CHC}$ and 53 (IQR 48,59) years for HCV uninfected controls. Ninety-six per cent were males and $54 \%$ were White. Persons with CHC were more likely to be homeless $(21.7 \%$ vs. $11.2 \%$; $<0.0001)$, reside in an urban area (73.3\% vs. $67.9 \%$; $\mathrm{P}<0.0001)$ and in the low income or below federal poverty level group $(94.5 \%$ vs. $89.7 \%$; $\mathrm{P}<$ 0.0001). Persons with $\mathrm{CHC}$ infection were also more likely to have a psychiatric diagnosis (32.1\% vs. $25.6 \%$; $<0.0001)$.

Acute POU was numerically similar in both groups (38.4\% vs. $37.9 \%$; $\mathrm{P}=0.01)$; however long-term POU was higher among persons with $\mathrm{CHC}(32.3 \%$ vs. $23.1 \%)$ driven entirely by chronic long-term use $(28.4 \%$ vs. $19.2 \%$ ) with no difference in episodic long-term use (3.9\% vs. $3.9 \%)$. Proportion of persons with 3 or more social vulnerability factors was higher among persons with $\mathrm{CHC}(48.8 \%$ vs. $39.5 \%)$.

We compared the baseline characteristics of persons with and without $\mathrm{CHC}$ after excluding those with missing data to ensure that the overall characteristics were not different in the analysis cohort. The results were nearly identical to the main analysis results (Supplementary Table 1). 


\begin{tabular}{|c|c|c|c|}
\hline & $\begin{array}{l}\text { CHC } \\
N=160,856\end{array}$ & $\begin{array}{l}\text { HCV- } \\
N=160,856\end{array}$ & P-value \\
\hline Age, median (IQR) & $54(49,59)$ & $53(48,59)$ & $<0.0001$ \\
\hline Race & & & $<0.0001$ \\
\hline White & $54.0 \%$ & $54.3 \%$ & \\
\hline Black & $30.0 \%$ & $29.2 \%$ & \\
\hline Hispanic & $3.5 \%$ & $3.6 \%$ & \\
\hline Others/unknown & $12.5 \%$ & $12.9 \%$ & \\
\hline Male sex & $96.6 \%$ & $96.4 \%$ & 0.0003 \\
\hline Diabetes & $5.9 \%$ & $5.1 \%$ & $<0.0001$ \\
\hline Hypertension & $44.5 \%$ & $43.7 \%$ & $<0.0001$ \\
\hline Cardiovascular disease & $10.1 \%$ & $9.9 \%$ & 0.08 \\
\hline Cancer diagnosis & $6.4 \%$ & $5.2 \%$ & $<0.0001$ \\
\hline Alcohol use disorder & $36.6 \%$ & $26.0 \%$ & $<0.0001$ \\
\hline Smoking & & & $<0.0001$ \\
\hline Former & $53.0 \%$ & $51.6 \%$ & \\
\hline Never & $13.7 \%$ & $14.4 \%$ & \\
\hline Current & $11.6 \%$ & $9.3 \%$ & \\
\hline Unknown & $21.7 \%$ & $24.7 \%$ & \\
\hline Homeless & $21.7 \%$ & $11.2 \%$ & $<0.0001$ \\
\hline Residence & & & $<0.0001$ \\
\hline Highly rural & $0.9 \%$ & $1.2 \%$ & \\
\hline Rural & $25.8 \%$ & $31.0 \%$ & \\
\hline Urban & $73.3 \%$ & $67.9 \%$ & \\
\hline Income level & & & $<0.0001$ \\
\hline$<21,330$ (below Federal poverty level) & $71.5 \%$ & $60.8 \%$ & \\
\hline $21,330-45,200$ (low income) & $22.9 \%$ & $28.9 \%$ & \\
\hline $45,201-135,600$ (middle class) & $5.3 \%$ & $9.7 \%$ & \\
\hline$>135,600$ (high income) & $0.2 \%$ & $0.6 \%$ & \\
\hline Any psychiatric diagnosis & $32.1 \%$ & $25.6 \%$ & $<0.0001$ \\
\hline Major depression & $15.3 \%$ & $11.2 \%$ & $<0.0001$ \\
\hline Schizophrenia & $6.1 \%$ & $4.6 \%$ & $<0.0001$ \\
\hline Bipolar disorder & $9.0 \%$ & $5.5 \%$ & $<0.0001$ \\
\hline Post-traumatic stress disorder & $17.1 \%$ & $13.5 \%$ & $<0.0001$ \\
\hline Acute prescription opioid use & $38.4 \%$ & $37.9 \%$ & 0.01 \\
\hline Long-term prescription opioid use & $32.3 \%$ & $23.1 \%$ & $<0.0001$ \\
\hline Episodic long-term & $3.9 \%$ & $3.9 \%$ & 0.54 \\
\hline Chronic long-term & $28.4 \%$ & $19.2 \%$ & $<0.0001$ \\
\hline Three or more social vulnerability factors & $48.8 \%$ & $39.5 \%$ & $<0.0001$ \\
\hline
\end{tabular}

Table 1. Baseline characteristics of persons with $\mathrm{CHC}$ and propensity score matched $\mathrm{HCV}$-uninfected controls. $\mathrm{HCV}$, hepatitis $\mathrm{C}$ virus; $\mathrm{CHC}$, chronic hepatitis $\mathrm{C}$ virus infection.

Baseline characteristics: POU+ vs POU-. Persons with any POU (acute or long-term) were more likely to have comorbid conditions including diabetes (6.6\% vs. 3.4\%), hypertension ( $47.0 \%$ vs. 38.6\%), cardiovascular disease (11.4\% vs. $7.2 \%)$, cancer diagnosis (7.0\% vs. 3.5\%) and alcohol use disorder (34.6\% vs. $24.9 \%)$ compared with those with no POU ( $<0.0001$ for all comparisons) (Table 2). They were also more likely to be homeless (18.3\% vs. $12.9 \%)$, have lower income level (67.3\% vs. $64.1 \%$ below the Federal poverty line) and a diagnosis of psychiatric illness $(32.5 \%$ vs. $21.8 \%)$ ( $\mathrm{P}<0.0001$ for all comparisons).

We compared the baseline characteristics of persons with and without POU after excluding those with missing data to ensure that the overall characteristics were not different in the analysis cohort. The results were nearly identical to the main analysis results (Supplementary Table 2).

POU by social vulnerability factors. Proportion of persons with POU increased with increasing number of social vulnerability factors (Table 3). Among persons with acute POU, $29.46 \%$ had no social vulnerability factors, while among those with long-term episodic POU, $2.32 \%$ had no social vulnerability factor, and among those with long-term chronic POU, $11.99 \%$ had no social vulnerability factor. These proportions were higher for persons with any social vulnerability factor. However, there was no discernible relationship with increasing number of social vulnerability factors and higher rates of POU (Table 3). 


\begin{tabular}{|c|c|c|c|}
\hline & $\begin{array}{l}\text { POU+ } \\
\mathrm{N}=211,799\end{array}$ & $\begin{array}{l}\text { POU- } \\
\mathrm{N}=109,913\end{array}$ & P-value \\
\hline Age, median (IQR) & $53(48,58)$ & $55(49,61)$ & $<0.0001$ \\
\hline Race, $\%$ & & & $<0.0001$ \\
\hline White & $54.6 \%$ & $53.3 \%$ & \\
\hline Black & $31.2 \%$ & $26.5 \%$ & \\
\hline Hispanic & $3.8 \%$ & $3.2 \%$ & \\
\hline Others/unknown & $10.5 \%$ & $17.0 \%$ & \\
\hline Sex, $\%$ male & $96.4 \%$ & $96.7 \%$ & 0.0002 \\
\hline Diabetes, \% & $6.6 \%$ & $3.4 \%$ & $<0.0001$ \\
\hline Hypertension, \% & $47.0 \%$ & $38.6 \%$ & $<0.0001$ \\
\hline Cardiovascular disease, $\%$ & $11.4 \%$ & $7.2 \%$ & $<0.0001$ \\
\hline Cancer diagnosis, $\%$ & $7.0 \%$ & $3.5 \%$ & $<0.0001$ \\
\hline Alcohol use disorder, $\%$ & $34.6 \%$ & $24.9 \%$ & $<0.0001$ \\
\hline Smoking, \% & & & $<0.0001$ \\
\hline Current & $53.9 \%$ & $49.2 \%$ & \\
\hline Former & $12.8 \%$ & $16.4 \%$ & \\
\hline Never & $9.8 \%$ & $11.7 \%$ & \\
\hline Unknown & $23.4 \%$ & $22.7 \%$ & \\
\hline Homeless & $18.3 \%$ & $12.9 \%$ & $<0.0001$ \\
\hline Residence & & & $<0.0001$ \\
\hline Highly rural & $1.0 \%$ & $1.1 \%$ & \\
\hline Rural & $28.0 \%$ & $29.2 \%$ & \\
\hline Urban & $71.0 \%$ & $69.8 \%$ & \\
\hline Income level & & & $<0.0001$ \\
\hline$<21,330$ (below Federal poverty level) & $67.3 \%$ & $64.1 \%$ & \\
\hline $21,330-45,200$ (low income) & $26.8 \%$ & $24.3 \%$ & \\
\hline $45,201-135,600$ (middle class) & $5.8 \%$ & $10.8 \%$ & \\
\hline$>135,600$ (high income) & $0.2 \%$ & $0.9 \%$ & \\
\hline Any psychiatric diagnosis, $\%$ & $32.5 \%$ & $21.8 \%$ & $<0.0001$ \\
\hline Major depression, $\%$ & $15.6 \%$ & $8.8 \%$ & $<0.0001$ \\
\hline Schizophrenia, \% & $5.6 \%$ & $4.8 \%$ & $<0.0001$ \\
\hline Bipolar disorder, $\%$ & $8.3 \%$ & $5.0 \%$ & $<0.0001$ \\
\hline Post-traumatic stress disorder, $\%$ & $17.7 \%$ & $10.7 \%$ & $<0.0001$ \\
\hline
\end{tabular}

Table 2. Baseline characteristics of persons with and without any acute or chronic prescription opioid use. POU, prescription opioid use.

\begin{tabular}{|l|r|l|l|l|}
\hline & N & Acute POU, $\%$ & Long-term episodic POU, \% & Long-term chronic POU, \% \\
\hline No factor & 6080 & 29.5 & 2.3 & 12.0 \\
\hline Any one factor & 315,632 & 38.3 & 3.9 & 24.0 \\
\hline Any two factors & 258,280 & 39.0 & 4.1 & 24.7 \\
\hline Any three factors & 142,124 & 40.5 & 4.2 & 26.3 \\
\hline Any four factors & 60,785 & 42.7 & 4.2 & 27.7 \\
\hline Any five factors & 17,344 & 44.0 & 4.5 & 28.4 \\
\hline Any six factors & 1759 & 42.7 & 4.7 & 30.5 \\
\hline All seven factors & 28 & 35.7 & 3.6 & 25.0 \\
\hline
\end{tabular}

Table 3. Prescription opioid use by number of social vulnerability factors (non-white race, females, homelessness, poverty income $<\$ 45,200$, rural or highly rural residence, alcohol use disorder, psychiatric illness). POU, prescription opioid use.

Factors associated with POU. We determined the factors associated with acute, episodic long-term and chronic long-term POU. Increasing age was associated with lower risk of all types of POU. Black and Hispanic races were associated with a higher risk of acute and episodic long-term POU but with a lower risk of chronic long-term use (Table 4). Medical comorbidities (diabetes, cardiovascular disease, cancer) were associated with a higher risk of all types of POU. Rural and highly rural residence were associated with a lower risk of acute POU, 


\begin{tabular}{|c|c|c|c|c|c|c|}
\hline & \multicolumn{2}{|l|}{ Acute POU } & \multicolumn{2}{|c|}{$\begin{array}{l}\text { Long-term episodic } \\
\text { POU }\end{array}$} & \multicolumn{2}{|c|}{ Long-term chronic POU } \\
\hline & Odds ratio & $95 \% \mathrm{CI}$ & Odds ratio & 95\% CI & Odds ratio & 95\% CI \\
\hline Age, per 10-year increase & 0.92 & $0.91,0.92$ & 0.91 & $0.89,0.93$ & 0.79 & \begin{tabular}{|l}
$0.78,0.80$ \\
\end{tabular} \\
\hline \multicolumn{7}{|l|}{ Race (comparator: white) } \\
\hline Black & 1.34 & $1.32,1.36$ & 1.29 & $1.23,1.34$ & 0.71 & $0.70,0.73$ \\
\hline Hispanic & 1.50 & $1.44,1.55$ & 1.22 & $1.11,1.34$ & 0.66 & $0.62,0.69$ \\
\hline Others/unknown & 0.92 & $0.9,0.94$ & 0.88 & $0.82,0.93$ & 0.66 & $0.65,0.68$ \\
\hline Male sex (vs. female) & 0.96 & $0.92,1.00$ & 0.81 & $0.74,0.89$ & 1.14 & $1.09,1.19$ \\
\hline Diabetes & 1.16 & $1.13,1.20$ & 1.36 & $1.27,1.45$ & 1.24 & $1.19,1.28$ \\
\hline Hypertension & 1.01 & $0.99,1.02$ & 1.32 & $1.26,1.37$ & 1.48 & $1.45,1.50$ \\
\hline Cardiovascular disease & 1.11 & $1.08,1.13$ & 1.37 & $1.30,1.45$ & 1.25 & $1.22,1.29$ \\
\hline Cancer diagnosis & 1.22 & $1.19,1.26$ & 1.52 & $1.43,1.63$ & 1.68 & $1.63,1.74$ \\
\hline Alcohol use disorder & 1.17 & $1.15,1.19$ & 0.94 & $0.90,0.99$ & 0.98 & $0.96,1.00$ \\
\hline \multicolumn{7}{|l|}{ Smoking (comparator: never) } \\
\hline Former & 0.96 & $0.93,0.98$ & 0.99 & $0.92,1.06$ & 1.09 & $1.05,1.13$ \\
\hline Current & 0.94 & $0.91,0.96$ & 0.96 & $0.90,1.02$ & 1.45 & $1.41,1.50$ \\
\hline Unknown & 0.98 & $0.96,1.01$ & 1.07 & $1.00,1.14$ & 1.38 & $1.34,1.43$ \\
\hline Homeless (vs. not homeless) & 1.12 & $1.09,1.14$ & 0.91 & $0.86,0.96$ & 0.92 & $0.90,0.95$ \\
\hline \multicolumn{7}{|l|}{ Residence (vs. urban residence) } \\
\hline Rural residence & 0.83 & $0.82,0.85$ & 1.05 & $1.01,1.09$ & 1.27 & $1.25,1.30$ \\
\hline Highly rural residence & 0.82 & $0.76,0.88$ & 0.99 & $0.82,1.20$ & 1.37 & $1.27,1.49$ \\
\hline \multicolumn{7}{|l|}{ Income level (vs. < 21,330) } \\
\hline $21,330-45,200$ (low income) & 1.09 & $1.07,1.11$ & 1.17 & $1.12,1.22$ & 0.98 & $0.96,0.99$ \\
\hline $45,201-135,600$ (middle class) & 0.92 & $0.90,0.95$ & 0.89 & $0.82,0.96$ & 0.56 & $0.54,0.59$ \\
\hline$>135,600$ (high income) & 0.5 & $0.44,0.58$ & 0.51 & $0.34,0.77$ & 0.23 & $0.18,0.29$ \\
\hline Psychiatric illness & 1.00 & $0.98,1.01$ & 1.19 & $1.14,1.24$ & 1.39 & $1.36,1.41$ \\
\hline $\mathrm{CHC}$ & 0.98 & $0.96,0.99$ & 0.99 & $0.95,1.03$ & 1.66 & $1.63,1.69$ \\
\hline
\end{tabular}

Table 4. Predictors of prescription opioid use (multivariable logistic regression model). CHC, chronic hepatitis $\mathrm{C}$ virus infection; POU, prescription opioid use.

but a higher risk of chronic long-term POU. Higher income strata were associated with a lower risk of all types of POU. CHC infection was not associated with episodic long-term POU (OR 0.99, 95\% CI 0.95, 1.03), but was significantly associated with chronic long-term POU (OR 1.66, 95\% CI 1.63, 1.69) (Table 4). Presence of any social vulnerability factor was associated with a higher risk of acute, episodic long-term and chronic long-term POU, with increasing number of factors associated with a generally higher risk, though the relationship was not clearly linear (Supplementary Table 3).

\section{Discussion}

We provide the first comprehensive picture of POU in persons with $\mathrm{CHC}$ and appropriately matched controls in the context of social vulnerability. We found that $\mathrm{CHC}$ and multiple social vulnerability factors are associated with a higher risk of chronic long-term POU, but not necessarily acute POU.

We found that $\mathrm{CHC}$ was associated with a significantly higher risk of chronic long-term POU but not with a higher risk of acute or episodic long-term POU. In fact, CHC was among the strongest risk factor for POU with the odds ratio similar to cancer diagnosis. $\mathrm{CHC}$ is associated with a higher burden of medical and psychiatric comorbidities and several extrahepatic manifestations ${ }^{34,35}$. Chronic pain is often associated with CHC infection itself, or with one of several rheumatologic or immunologic manifestations of CHC infection, with up to two-thirds of the patients with $\mathrm{CHC}$ experiencing chronic pain ${ }^{35,36}$. In the interferon-era, treatment itself was associated with chronic fatigue and pain. However, since only a small fraction of persons were ever treated with interferon-based regimens, other factors certainly contributed to chronic pain ${ }^{37}$. Newer all-oral direct acting antiviral agents are more tolerable, more efficacious and have fewer side effects. Whether treatment with these newer agents is associated with a lower incidence of pain or resolution of chronic pain requires further study. Such positive association may in turn reduce the need for opioid prescriptions and its downstream consequences. On the other hand, the association between $\mathrm{CHC}$ and POU could be due to POU leading to injection drug use, which increases the risk of acquiring CHC. Future studies should also determine the direction of association between $\mathrm{CHC}$ and POU.

Persons with POU were more likely to have medical comorbidities. While most comorbidities studied do not necessarily require opioids, they may be a surrogate for other associated conditions. We also found POU to be more common among persons with several individual social vulnerability factors. These included Black race, homelessness, lower income strata and psychiatric illness. Rural or highly rural residence was not associated with a higher rate of POU. However, in logistic regression model, male sex was associated with a lower risk of 
acute or episodic long-term POU but a higher risk of chronic long-term POU. Whether females have actually lesser need for chronic long-term opioids, or whether this is due to lesser access to resources or perception of providers is unknown and warrants further study. Risk of POU was significantly lower in persons with higher income strata independent of other factors studied confirming that persons in lower economic strata are most hardly hit by POU, and by extension possibly opioid use disorder. This highlights co-occurrence of syndemics of socioeconomic marginalization and other vulnerability factors with POU use, which could be related to eventual opioid use disorders.

These findings, taken together, indicate a strong association between POU and socially vulnerable $\mathrm{CHC}$ infected persons. Since opioid analgesics are frequently prescribed for appropriate medical conditions, an important next step is to determine the proportion of persons using opioid analgesics strictly as prescribed, and to determine the magnitude and factors associated with inappropriate use. Subsequent studies should also determine the proportion of persons with POU progressing to OUD and injection drug use, and risk factors associated with such progression.

Strengths of our study include a large national population and appropriately matched controls. Veterans have a high burden of medical, psychiatric and substance use comorbidities. While this is not truly representative of the overall population, it is critical to understand the magnitude and impact of this epidemic in this particularly high-risk population. A main limitation of the current study is that we only studied POU and not the downstream consequences, namely OUD and illicit injection drug use. However, our specific aim for this study was limited to understanding the first step in this cascade and future studies will look into these downstream effects and clinical consequences. Another limitation of our study is the absence of a quantitative measure of pain which may require opioid prescription. To mitigate this at least partially, we excluded persons with common conditions associated with short-term POU, including acute fractures and dental work, as well as chronic painful conditions like cancer. Our study does not address the question of temporal relationships between POU, injection drug use and $\mathrm{CHC}$ infection, since this was not the aim of our study.

In conclusion, persons with $\mathrm{CHC}$ have high prevalence of social vulnerability factors, and a higher risk of chronic long-term POU. Consequences of high rate and risk of POU among this population need further study.

Received: 19 November 2020; Accepted: 15 February 2021

Published online: 15 March 2021

\section{References}

1. Vijay, A., Rhee, T. G. \& Ross, J. S. U. S. prescribing trends of fentanyl, opioids, and other pain medications in outpatient and emergency department visits from 2006 to 2015. Prev. Med. 123, 123-129 (2019).

2. Merino, R., Bowden, N., Katamneni, S. \& Coustasse, A. The Opioid Epidemic in West Virginia. Health Care Manag (Frederick) 2019.

3. Rose, C. et al. Mortality associated with opioid overdose: A review of clinical characteristics and health services received in the year prior to death. Psychiatr. Serv. 70, 90-96 (2019).

4. Garcia, M. C. et al. Opioid prescribing rates in nonmetropolitan and metropolitan counties among primary care providers using an electronic health record system-United States, 2014-2017. MMWR Morb. Mortal Wkly. Rep. 68, 25-30 (2019).

5. Han, B. H., Sherman, S. E. \& Palamar, J. J. Prescription opioid misuse among middle-aged and older adults in the United States, 2015-2016. Prev. Med. 121, 94-98 (2019).

6. Bohnert, A. S. B. et al. Association between opioid prescribing patterns and opioid overdose-related deaths. JAMA 305, 1315-1321 (2011).

7. SAMHSA. Substance Abuse and Mental Health Services Administration. Key substance use and mental health indicators in the United States: Results from the 2018 National Survey on Drug Use and Health (HHS Publication No. PEP19-5068, NSDUH Series H-54). https://www.samhsa.gov/data/ (Accessed 10 May 2020) (Center for Behavioral Health Statistics and Quality, Substance Abuse and Mental Health Services Administration, 2019).

8. Wilson, N., Kariisa, M., Seth, P., Smith, H. T. \& Davis, N. L. Drug and opioid-involved overdose deaths-United States, $2017-2018$. MMWR Morb. Mortal. Wkly. Rep. 69, 290-297 (2020).

9. Hedegaard, H., Miniño, A. \& Warner, M. Drug overdose deaths in the United States, 1999-2018. NCHS Data Brief, no 356 (National Center for Health Statistics, 2020).

10. Warfield, S., Pollini, R., Stokes, C. M. \& Bossarte, R. Opioid-related outcomes in West Virginia, 2008-2016. Am. J. Public Health 109, 303-305 (2019).

11. Kiang, M. V., Basu, S., Chen, J. \& Alexander, M. J. Assessment of changes in the geographical distribution of opioid-related mortality across the United States by opioid type, 1999-2016. JAMA Netw. Open 2, e190040 (2019).

12. Puzhko, S. et al. High hepatitis $C$ incidence in relation to prescription opioid injection and poly-drug use: Assessing barriers to hepatitis C prevention. Int. J. Drug Policy 47, 61-68 (2017).

13. Bruneau, J., Arruda, N., Zang, G., Jutras-Aswad, D. \& Roy, E. The evolving drug epidemic of prescription opioid injection and its association with HCV transmission among people who inject drugs in Montreal, Canada. Addiction 114, 366-373 (2019).

14. Zibbell, J. E. et al. Increases in acute hepatitis $C$ virus infection related to a growing opioid epidemic and associated injection drug use, United States, 2004 to 2014. Am. J. Public Health 108, 175-181 (2018).

15. Butt, A. A., Khan, U. A., McGinnis, K. A., Skanderson, M. \& Kwoh, C. K. Co-morbid medical and psychiatric illness and substance abuse in HCV-infected and uninfected veterans. J. Viral Hepatitis 14, 890-896 (2007).

16. El Serag, H. B., Kunik, M., Richardson, P. \& Rabeneck, L. Psychiatric disorders among veterans with hepatitis C infection. Gastroenterology 123, 476-482 (2002).

17. Downie, D. L. et al. Racial disparities in blood pressure control and treatment differences in a Medicaid population, North Carolina, 2005-2006. Prev. Chronic Dis. 8, A55 (2011).

18. Langabeer, J. R. et al. Disparities between US opioid overdose deaths and treatment capacity: A geospatial and descriptive analysis. J. Addict. Med. 13(6), 476-482 (2019).

19. Gordon, A. J. et al. Associations between alcohol use and homelessness with healthcare utilization among human immunodeficiency virus-infected veterans. Med. Care 44, S37-S43 (2006).

20. Cheung, R. C., Hanson, A. K., Maganti, K., Keeffe, E. B. \& Matsui, S. M. Viral hepatitis and other infectious diseases in a homeless population. J. Clin. Gastroenterol. 34, 476-480 (2002). 
21. Alter, M. J. et al. The prevalence of hepatitis C virus infection in the United States, 1988 through 1994. N. Engl. J. Med. 341, 556-562 (1999).

22. Chirikos, T. N., Roetzheim, R. G., McCarthy, E. P. \& Iezzoni, L. I. Cost disparities in lung cancer treatment by disability status, sex, and race. Disabil. Health J. 1, 108-115 (2008).

23. Iezzoni, L. I. et al. Treatment disparities for disabled medicare beneficiaries with stage I non-small cell lung cancer. Arch. Phys. Med. Rehabil. 89, 595-601 (2008).

24. Chen, J. Y. et al. Tricyclic antidepressant use and the risk of fibrosis progression in hepatitis C-infected persons: Results from ERCHIVES. J. Viral Hepat. 25, 825-833 (2018).

25. Li, D. K., Yan, P., Abou-Samra, A. B., Chung, R. T. \& Butt, A. A. Proton pump inhibitors are associated with accelerated development of cirrhosis, hepatic decompensation and hepatocellular carcinoma in noncirrhotic patients with chronic hepatitis $\mathrm{C}$ infection: Results from ERCHIVES. Aliment Pharmacol. Ther. 47, 246-258 (2018).

26. Li, D. K. et al. The short-term incidence of hepatocellular carcinoma is not increased after hepatitis $\mathrm{C}$ treatment with direct-acting antivirals: An ERCHIVES study. Hepatology 67, 2244-2253 (2018).

27. Butt, A. A., Yan, P., Aslam, S., Shaikh, O. S. \& Abou-Samra, A. B. Hepatitis C virus (HCV) treatment with directly acting agents reduces the risk of incident diabetes: Results from electronically retrieved cohort of HCV infected veterans (ERCHIVES). Clin. Infect. Dis. 70, 1153-1160 (2020).

28. Butt, A. A. et al. Hepatitis C virologic response in hepatitis B and C coinfected persons treated with directly acting antiviral agents: Results from ERCHIVES. Int. J. Infect Dis. 92, 184-188 (2020).

29. Butt, A. A. et al. Treatment of HCV reduces viral hepatitis-associated liver-related mortality in patients: An ERCHIVES study. J. Hepatol. https://doi.org/10.1016/j.jhep.2020.02.022 (2020).

30. Butt, A. A. et al. HIV infection and the risk of diabetes mellitus. AIDS 23, 1227-1234 (2009).

31. Butt, A. A. et al. Liver fibrosis progression in hepatitis $C$ virus infection after seroconversion. JAMA Intern. Med. 175, 178-185 (2015).

32. Butt, A. A., Khan, U. A., McGinnis, K. A., Skanderson, M. \& Kent, K. C. Co-morbid medical and psychiatric illness and substance abuse in HCV-infected and uninfected veterans. J. Viral Hepat. 14, 890-896 (2007).

33. Butt, A. A. et al. Direct-acting antiviral therapy for HCV infection is associated with a reduced risk of cardiovascular disease events. Gastroenterology 156, 987-996 (2019).

34. Mohanty, A., Salameh, S. \& Butt, A. A. Impact of direct acting antiviral agent therapy upon extrahepatic manifestations of hepatitis C virus infection. Curr. HIV/AIDS Rep. 16, 389-394 (2019).

35. Silberbogen, A. K., Janke, E. A. \& Hebenstreit, C. A closer look at pain and hepatitis C: Preliminary data from a veteran population. J. Rehabil. Res. Dev. 44, 231-244 (2007)

36. Lovejoy, T. I., Dobscha, S. K., Cavanagh, R., Turk, D. C. \& Morasco, B. J. Chronic pain treatment and health service utilization of veterans with hepatitis C virus infection. Pain Med. 13, 1407-1416 (2012).

37. Butt, A. A. et al. Rate and predictors of treatment prescription for hepatitis C. Gut 56, 385-389 (2007).

\section{Acknowledgements}

This material is the result of work supported with resources and the use of facilities at the VA Pittsburgh Healthcare System and the central data repositories maintained by the VA Information Resource Center, including the National Patient Care Database, Decisions Support System Database and Pharmacy Benefits Management Database. The work is also supported by the National Institute of Drug Abuse (K01 048172 to SNK). The views expressed in this article are those of the authors and do not necessarily reflect the position or policy of the Department of Veterans Affairs or the funding agencies.

\section{Author contributions}

A.A.B.: study concept and design; acquisition of data; analysis and interpretation of data; drafting of the manuscript; critical revision of the manuscript for important intellectual content; obtained funding; P.Y.: acquisition of data; statistical analysis; S.K., N.J.: critical revision of the manuscript for important intellectual content; AB.-AS.: critical revision of the manuscript for important intellectual content; S.I.: analysis and interpretation of data; critical revision of the manuscript for important intellectual content; Authorship statement: A.A.B. had complete access to data at all times and accepts the responsibility of the integrity of this article.

\section{Competing interests}

Dr. Kapadia has received grants paid to his institution from Gilead Sciences Inc for research related to hepatitis C, unrelated to the current work. All other authors have no potential conflicts of interest to disclose.

\section{Additional information}

Supplementary Information The online version contains supplementary material available at https://doi. org/10.1038/s41598-021-85283-6.

Correspondence and requests for materials should be addressed to A.A.B.

Reprints and permissions information is available at www.nature.com/reprints.

Publisher's note Springer Nature remains neutral with regard to jurisdictional claims in published maps and institutional affiliations. 
(c) (i) Open Access This article is licensed under a Creative Commons Attribution 4.0 International cc) License, which permits use, sharing, adaptation, distribution and reproduction in any medium or format, as long as you give appropriate credit to the original author(s) and the source, provide a link to the Creative Commons licence, and indicate if changes were made. The images or other third party material in this article are included in the article's Creative Commons licence, unless indicated otherwise in a credit line to the material. If material is not included in the article's Creative Commons licence and your intended use is not permitted by statutory regulation or exceeds the permitted use, you will need to obtain permission directly from the copyright holder. To view a copy of this licence, visit http://creativecommons.org/licenses/by/4.0/.

(C) The Author(s) 2021 